\title{
Effect of PEEP and l:E ratio on cerebral oxygenation in ARDS: an experimental study in anesthetized rabbit
}

\author{
Federica Lovisari ${ }^{1,2}$, Gergely H. Fodor ${ }^{1}$, Ferenc Peták ${ }^{3}$, Walid Habre ${ }^{1,4}$ and Sam Bayat ${ }^{1,5,6^{*}}$ (D)
}

\begin{abstract}
Background: Although PEEP and inversed I:E ratio have been shown to improve gas exchange in ARDS, both can adversely affect systemic hemodynamics and cerebral perfusion. The goal of this study was to assess how changes in PEEP and I:E ratio affect systemic and cerebral oxygenation and perfusion in normal and injured lung.

Methods: Eight anesthetized Chinchilla-Bastard rabbits were ventilated at baseline with pressure-regulated volume control mode, $\mathrm{V}_{\mathrm{T}}=6 \mathrm{ml} / \mathrm{kg}, \mathrm{PEEP}=6 \mathrm{cmH}_{2} \mathrm{O}, \mathrm{FIO}_{2}=0.4$; respiratory rate set for $\mathrm{ETCO}_{2}=5.5 \%$, and $\mathrm{l}: \mathrm{E}=1: 2$, 1:1 or 2:1 in random order. Ultrasonic carotid artery flow (CF), arterial $\left(\mathrm{PaO}_{2}\right)$, jugular venous blood gases and near infrared spectroscopic cerebral oxygenation $\left(\mathrm{AHBO}_{2}\right)$ were recorded for each experimental condition. After induced lung injury, the animals were ventilated with PEEP $=9$ followed by $6 \mathrm{cmH}_{2} \mathrm{O}$.

Results: At baseline, inverse-ratio ventilation (IRV) significantly reduced cerebral oxygenation $\left(\triangle \mathrm{O}_{2} \mathrm{HB}\right.$; -27 at $1: 2 ;-15$ at $1: 1$ vs. $0.27 \mu \mathrm{mol} / \mathrm{L}$ at $2: 1 ; p<0.05)$, due to a significant reduction in mean arterial pressure and CF without modifying gas exchange. In injured lung, IRV improved gas exchange but decreased cerebral perfusion without affecting brain oxygenation. The higher PEEP level, however, improved $\mathrm{PaO}_{2}(67.5 \pm 19.3$ vs. $42.2 \pm 8.4, p<$ 0.05), resulting in an improved $\Delta \mathrm{HBO}_{2}(-13.8 \pm 14.7$ vs. $-43.5 \pm 21.3, p<0.05)$, despite a drop in CF.
\end{abstract}

Conclusions: Our data suggest that unlike moderate PEEP, IRV is not effective in improving brain oxygenation in ARDS. In normal lung, IRV had a deleterious effect on brain oxygenation, which is relevant in anesthetized patients.

Keywords: Mechanical ventilation, Near-infrared spectrometry, Blood flow/regional, Acute respiratory distress syndrome, Lung function, Hemodynamics

\section{Background}

Positive-pressure mechanical ventilation is the mainstay of respiratory supportive therapy in patients with acute respiratory distress syndrome (ARDS) [1, 2]. The goal of mechanical ventilation in this setting is to open the alveoli and maintain lung aeration throughout the respiratory cycle, while avoiding excessive mechanical stretch on the lung tissue, and cyclic opening and closing of small airways and alveoli [3, 4], which can both lead to ventilator-induced lung injury. Application of positive end-expiratory pressure (PEEP) is one of the

\footnotetext{
* Correspondence: sbayat@chu-grenoble.fr

${ }^{1}$ Unit for Anesthesiological Investigations Department of Anesthesiology

Pharmacology and Intensive Care, University of Geneva, Geneva, Switzerland

${ }^{5}$ Inserm UA7 STROBE Laboratory, University of Grenoble, Grenoble, France

Full list of author information is available at the end of the article
}

main strategies for maintaining lung aeration following alveolar recruitment $[5,6]$. Another proposed approach is to increase the time during which positive pressure is applied at the airway opening, through inverse-ratio ventilation (IRV) [7-9]. This prolonged inspiratory time has been demonstrated to reduce alveolar collapse and to improve oxygenation in patients with ARDS $[10,11]$.

The beneficial effects of both PEEP and IRV, however, come at the potential cost of detrimental hemodynamic consequences, as the increase in intra-thoracic pressure reduces cardiac output, compromising peripheral tissue perfusion, and ultimately oxygenation [12]. Brain tissue oxygenation is directly affected by the changes in both systemic hemodynamics and blood oxygenation. It closely depends on blood perfusion and cellular metabolism in the brain, which are intricately and continuously 
coupled [13]. Moreover, cerebral blood flow is locally autoregulated within physiological limits of cerebral perfusion pressure $[14,15]$. Available data suggest that cerebrovascular autoregulation may be impaired in a significant number of patients with ARDS [16]. Currently, it is not well understood how the potentially conflicting effects of positive pressure ventilation settings, namely PEEP and ratio of inspiratory to expiratory time (I:E), on cerebral perfusion and blood oxygenation affect brain tissue oxygenation. The importance of understanding the impact of ventilator settings on brain oxygenation is further underscored by the high prevalence of cognitive impairment in ARDS survivors [17], where both mechanical ventilation [18] and brain tissue hypoxia [19] may play a causative role.

The aim of this study was to characterize how changes in PEEP and I:E ratio affect cerebral perfusion and brain tissue oxygenation in an experimental model of ARDS in anesthetized rabbits. We hypothesized that the improvements in gas exchange by either strategy could potentially improve brain oxygenation in the presence of lung injury.

\section{Methods}

\section{Ethics approval}

All experiments and procedures were conducted under approval from the Swiss Animal Welfare Committee (Geneva Cantonal Veterinary Office, registration number GE/164/15).

\section{Animal preparation}

Eight male pathogen-free Chinchilla-Bastard rabbits $(3.5 \pm 0.3 \mathrm{~kg})$, purchased from the University of Geneva (Animalerie d'Arare, Plan-les-Ouates, Switzerland), were sedated with intramuscular Xylazine (Provet SA, Lyssach, Switzerland; $5.0 \mathrm{mg} / \mathrm{kg}$ ). Following the insertion of a $22 \mathrm{G}$ catheter in a marginal ear vein, general anesthesia was initiated and maintained by a continuous infusion of propofol (B. Braun Medical AG, Sempach, Switzerland, $15-20 \mathrm{mg} / \mathrm{kg} / \mathrm{h}$ ) and fentanyl (Sintetica SA, Mendrisio, Switzerland; $5 \mu \mathrm{g} / \mathrm{kg} / \mathrm{h}$ ). All animals were intubated using a $3.0 \mathrm{~mm}$ cuffed endotracheal tube. Mechanical ventilation was initiated with the pressurecontrolled mode using a pediatric respirator (SERVO-i, Maquet Critical Care, Solna Sweden), with, at baseline: a fraction of inspired oxygen $\left(\mathrm{FiO}_{2}\right)$ of 0.4 , a PEEP of 3 $\mathrm{cmH}_{2} \mathrm{O}$ and an inspiratory pressure of $6 \mathrm{cmH}_{2} \mathrm{O}$ above PEEP. Tidal volume (VT) was approximately $6 \mathrm{ml} / \mathrm{kg}$ and respiratory rate (RR) was adjusted to maintain endtidal $\mathrm{CO}_{2}\left(\mathrm{ETCO}_{2}\right)$ between 5.5 and $6 \%$.

After ensuring proper depth of anesthesia, muscle relaxation was induced by a continuous infusion of atracurium (Tracrium, Labatec Pharma SA, Meyrin, Switzerland; $0.6 \mathrm{mg} / \mathrm{kg} / \mathrm{h}$ ). Fluid status was maintained by an IV infusion of lactated Ringer's solution (Fresenius Kabi AG, Oberdorf, Switzerland; $4 \mathrm{ml} / \mathrm{kg} / \mathrm{h}$ ) after an initial bolus of 0.5 to $1.0 \mathrm{ml}$ per $\mathrm{kg}$ of hydroxyethyl starch at the time of anesthesia induction.

The right internal jugular vein was cannulated with a 16G catheter for monitoring central venous pressure (CVP; Arrow, Teleflex Medical Europe, Westmeath, Ireland). A second 20G catheter was inserted in the left internal jugular vein cranially to allow cerebral venous blood sampling for blood gas analysis (Abbott i-Stat Handheld, Abbott Medical, Baar/Zug, Switzerland). A Doppler ring probe was positioned around the left internal carotid artery for continuous carotid blood flow (CF) measurement (Transonic Systems, Ithaca, NY). The left femoral artery was cannulated $(22 \mathrm{G}$, Abbocath, Abbott Medical) for invasive blood pressure monitoring and arterial blood gas analysis. The electrocardiogram (ECG) was continuously monitored (Bio Amp, ADInstruments, Dunedin, New Zealand). The animals were placed on a thermostatic heating pad and internal body temperature was maintained at $38-39^{\circ} \mathrm{C}$ (Harvard Apparatus, South Natick, MA, USA). An alveolar recruitment maneuver was then performed by inflating the lungs twice to $25 \mathrm{cmH}_{2} \mathrm{O}$ for $15 \mathrm{~s}$ to standardize volume history. Arterial, central venous and respiratory pressure, ECG and CF signals were digitized and recorded at $1 \mathrm{kHz}$ using an analog/digital interface (Powerlab model 8/35, ADInstruments). Physiological parameters were allowed to stabilize for $15 \mathrm{~min}$ before starting the experimental protocol.

\section{Brain oxygenation monitoring by near-infrared spectroscopy}

Brain and muscle oxygenation was measured concomitantly to determine whether the observed changes in brain oxygenation result from local or systemic processes. Following appropriate skin shaving and cleaning, probes were placed on the head and the mid-dorsal region of the animal to monitor brain and muscle tissue oxygenation, using a NIRS monitor (NIRO-200NX, Hamamatsu, Solothurn, Switzerland). The device provides the following indices: the change in oxygenated hemoglobin $\left(\Delta \mathrm{HbO}_{2}\right)$, the change in deoxygenated hemoglobin $\left(\Delta \mathrm{HHO}_{2}\right)$, and the tissue oxygenation index (TOI), which is defined as the ratio of oxygenated to total tissue hemoglobin [20].

\section{Measurement of respiratory mechanics}

Mechanics of airways and respiratory tissue were measured using the forced oscillation technique, as detailed previously [21]. Briefly, a loudspeaker-in-box system was used to generate a small-amplitude (1 $\mathrm{cmH}_{2} \mathrm{O}$ peak to peak) composite pressure forcing signal in a frequency range of $0.5-21 \mathrm{~Hz}$ through the tracheal 
cannula during short (10s) pauses interposed with mechanical ventilation. A model including frequencyindependent airway resistance (Raw) and inertance (Iaw), in series with a constant-phase tissue model [22], including damping $(\mathrm{G})$ and elastance $(\mathrm{H})$ was fit to the respiratory impedance (Zrs) spectra. As previously established, Raw mainly reflects the flow resistance of the airways, Iaw is related to the cyclic acceleration and deceleration of the intra-thoracic gas, $G$ describes the energy loss within the respiratory tissues (resistance), and $\mathrm{H}$ characterizes the the respiratory tissues elastance. Raw and Iaw values were corrected by removing the instrumental components of the ET-cannula and the connecting tubing.

\section{Study protocol}

The study was performed in a single group $(n=8)$, each animal serving as its own control. The experiments were carried out at an academic laboratory between approximately $8 \mathrm{AM}$ and $4 \mathrm{PM}$. Fifteen minutes before baseline measurements, the ventilation mode was switched to pressure-regulated volume control mode, with a VT of 6 $\mathrm{ml} / \mathrm{kg}, \mathrm{FiO}_{2}$ of 0.4, PEEP of $6 \mathrm{cmH}_{2} \mathrm{O}$ and RR set to maintain $\mathrm{ETCO}_{2}$ between 5.5 and $6 \%$. The animals were then randomized to one of three different I:E ratios (1:2, 1:1 or $2: 1)$. After $10 \mathrm{~min}$ with the initial I:E ratio, arterial and jugular venous blood gases and respiratory mechanics data were collected, and the I:E ratio was changed in random order following a recruitment maneuver to reset lung volume history.

ARDS was subsequently induced by a bolus intravenous lipopolysaccharide injection (from Escherichia coli O111:B4, $300 \mu \mathrm{g} / \mathrm{kg}$, Sigma, Saint Louis, Missouri, USA) and whole lung lavage by instillation and recovery of 60 $\mathrm{ml}$ of $30^{\circ} \mathrm{C}$ normal saline 5 times through the tracheal cannula. This was followed by injurious ventilation using volume-controlled ventilation with a VT of $10 \mathrm{ml} / \mathrm{kg}$, a PEEP of 0 , a $\mathrm{FiO}_{2}$ of 1.0 and I:E ratio of 1:2, until an arterial oxygen tension $\left(\mathrm{PaO}_{2}\right)$ /fractional inspired oxygen $\left(\mathrm{FiO}_{2}\right)$ ratio between 100 and 200 was reached (in approximately 20 to $30 \mathrm{~min}$ ) which corresponds to moderate ARDS according to the Berlin definition [1]. Following the induction of ARDS, the same procedures performed at baseline were repeated, first at a PEEP of 9 $\mathrm{cmH}_{2} \mathrm{O}$ and again at PEEP of $6 \mathrm{cmH}_{2} \mathrm{O}$, and an $\mathrm{FIO}_{2}$ of 0.9. At the end of the study, the animal was euthanized by intravenous injection of sodium pentobarbital (120 $\mathrm{mg} / \mathrm{kg})$.

\section{Statistical analysis}

Data are presented as mean \pm standard error (SEM). Brain oxygenation indices were considered as the main outcome of the study. A formal sample size estimate could not be performed a priori since the variability of the main outcome parameter in rabbit was not known. Three-way repeated measures analysis of variance (ANOVA) with Dunnett's post hoc tests were used to assess the effects of lung injury (control vs. injured), PEEP level (6 vs. $9 \mathrm{cmH} 2 \mathrm{O}$ ) and I:E ratio (1:2, 1:1 and 2:1) on parameters reflecting ventilation, brain and muscle oxygenation, hemodynamics, and respiratory mechanics. The associations between hemodynamic and brain oxygenation indices were assessed with Pearson product-moment correlation tests. The statistical tests were performed within the $\mathrm{R}$ core package with the lme4 [23] and lsmeans [24] packages and SigmaPlot (version 12.5, Systat Software, Inc., Chicago, IL, USA) with a significance level of $p<0.05$, and all $p$ values were two-sided.

\section{Results}

The changes in airway pressures following the application of the different I:E ratios are shown in Fig. 1. Increasing I:E from 1:2 to 1:1 and 2:1 led to significant elevations in mean airway pressure regardless of the presence of injury $(p<0.001)$. In normal lungs, IRV resulted in both an increase in peak airway pressure (PIP, $p<0.05)$ and the appearance of a slight but significant

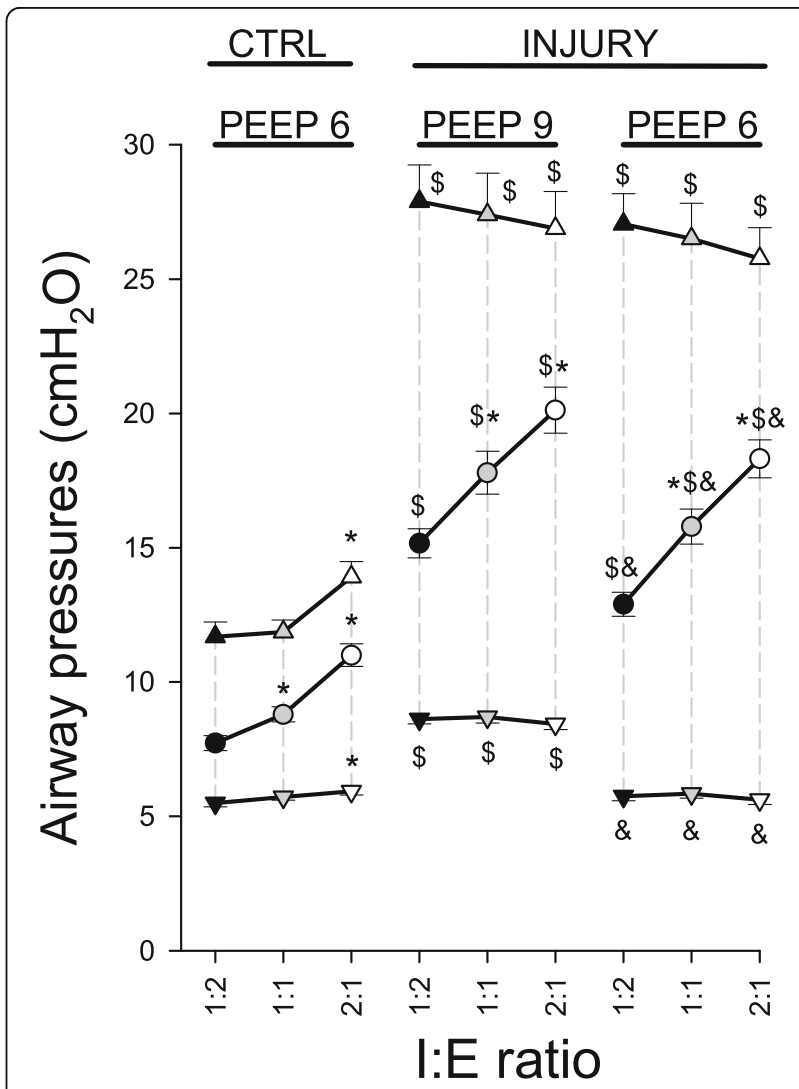

Fig. 1 Airway pressures. CTRL: control; triangles: peak airway pressure; circles: mean airway pressure; inverted triangles: end-expiratory pressure (PEEP); *: vs. 1:2; \$: vs. control; \&: vs. injury at PEEP $9 \mathrm{cmH}_{2} \mathrm{O}$ 
intrinsic PEEP $(p<0.05)$. Conversely, no change in PIP and PEEP was evident in injured lungs.

Figure 2 summarizes the effects of lung injury and the changes in I:E ratio on brain and peripheral muscle tissue oxygenation as measured by NIRS. Under the control conditions, IRV led to a significant decrease in $\Delta \mathrm{O}_{2} \mathrm{Hb}(p<0.05)$, whereas all other brain and muscle oxygenation indices remained constant. Induction of lung injury resulted in significant deterioration in these indices at the lower PEEP level $(p<0.05)$. These detrimental changes were effectively counteracted at the higher PEEP level in injured lungs $(p<0.05)$.

Changes in systemic hemodynamics are depicted in Fig. 3. Under control conditions, increasing the I:E ratio decreased venous return as suggested by the decrease in CVP $(p<0.005)$. The MAP $(p<0.02)$ and CF $(p<0.001)$ were also decreased significantly. Following the induction of lung injury, the observed hemodynamic changes were variable and influenced by both the PEEP level and the I:E ratio. IRV in the injured lungs led to significant changes in CVP $(p<0.05)$, HR $(p<0.002)$ and CF $(p<$ 0.02).
Figure 4 shows the main gas exchange parameters, and a complete picture of changes in blood gas parameters and brain oxygen uptake are shown in Table 1. Lung injury compromised gas exchange significantly, which was manifested in the drop in both arterial and jugular venous blood oxygen partial pressures $(p<0.05)$. Arterial and jugular venous $\mathrm{O}_{2}(p<0.001$ and $p<0.005$, respectively), $\mathrm{CO}_{2}$ partial pressures $(p<0.001$ and $p<0.01$, respectively) and $\mathrm{O}_{2}$ saturation $(p<0.001$ for both) were significantly higher at the higher PEEP level of 9 $\mathrm{cmH}_{2} \mathrm{O}$. Ventilation with IRV had no significant effect on arterial blood gas parameters in normal lungs. In the injured lungs however, applying an I:E ratio of 2:1 led to an improvement in $\mathrm{PaO}_{2}$ at both PEEP levels $(p<0.005)$.

Figure 5 presents the airway and respiratory tissue mechanical parameters. In the presence of the lower PEEP and a normal I:E ratio (1:2), lung injury resulted in marked and statistically significant increases in Raw $(p<0.002)$ and decreases in Iaw $(p<0.02)$. At the lower PEEP level, significant deteriorations in respiratory tissue mechanics were present in the injured lung independently of the I:E ratio applied $(p<0.05$ for all). The $\operatorname{Raw}(p<0.05)$, G
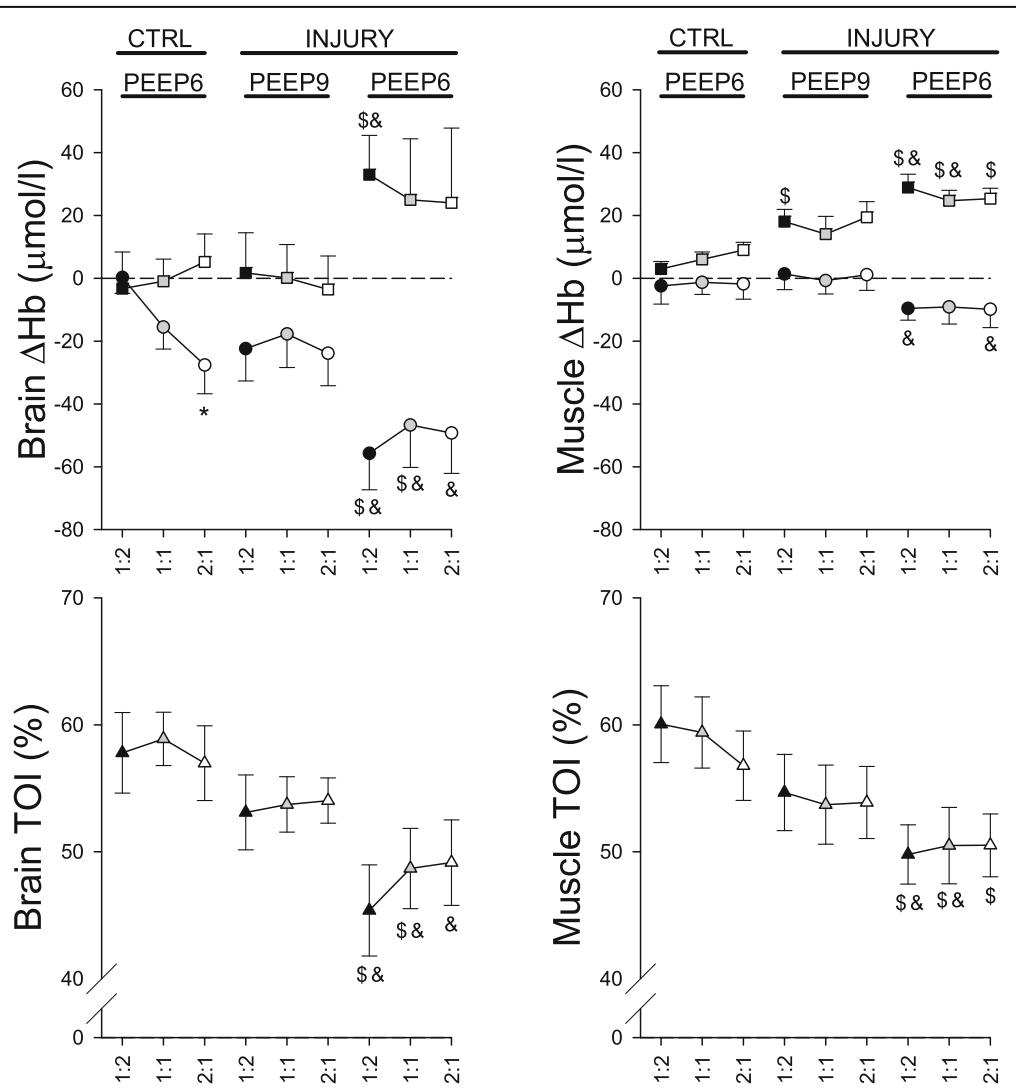

I:E ratio

Fig. 2 Oxygenation indices for brain and spinal muscle; $\Delta \mathrm{Hb}$ : change in hemoglobin; circles: change in oxygenated hemoglobin $\left(\Delta \mathrm{O}_{2} \mathrm{Hb}\right) ; \mathrm{squares}$ : change in deoxygenated hemoglobin $\left(\Delta \mathrm{HH}\right.$ ); triangles: tissue oxygenation index (TOI); ${ }^{*}$ : vs. 1:2; \$: vs. control; \&: vs. injury at PEEP $9 \mathrm{cmH}_{2} \mathrm{O}$ 

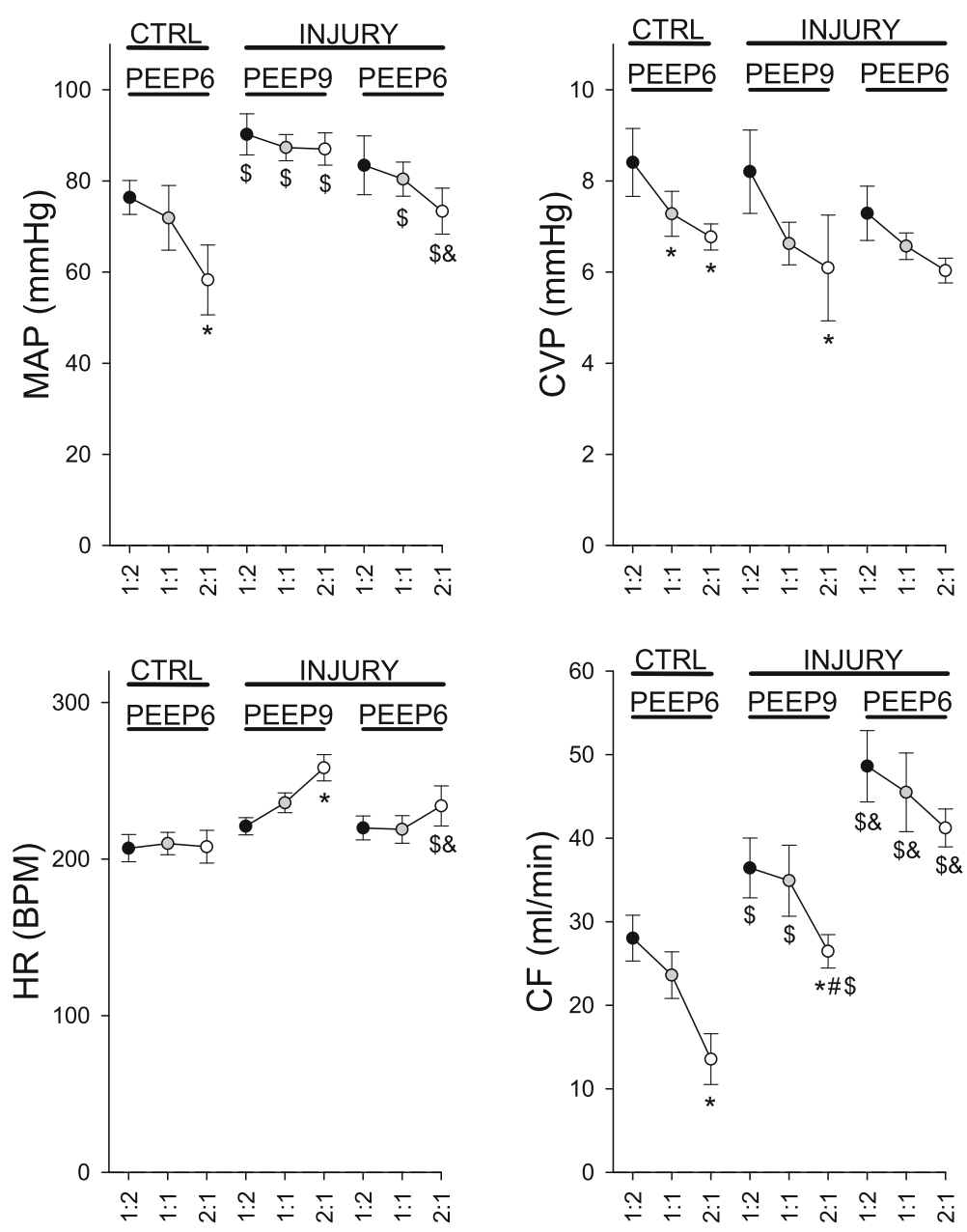

I:E ratio

Fig. 3 Hemodynamic parameters. CTRL: control; MAP: mean arterial pressure; CVP: central venous pressure; HR: heart rate; CF: carotid artery flow; *: vs. 1:2; \#: vs. 1:1; \$: vs. control; \&: vs. injury at PEEP $9 \mathrm{cmH}_{2} \mathrm{O}$

$(p<0.05)$ and $\mathrm{H}(p<0.03)$ were all significantly lower at the higher PEEP level of $9 \mathrm{cmH}_{2} \mathrm{O}$ in injured lungs.

\section{Discussion}

The main findings of this study were that in injured lungs, there was no evidence for an effect of IRV on brain oxygenation despite a positive effect on gas exchange. Conversely, in normal lungs, IRV led to a deterioration of brain oxygenation with a decrease in $\Delta \mathrm{O}_{2} \mathrm{Hb}$. This effect was consequent to the significant drop in both mean systemic arterial pressure (MAP) and CF. Unlike with IRV, brain oxygenation was significantly better with a moderate PEEP of $9 \mathrm{cmH}_{2} \mathrm{O}$ as compared to a lower PEEP level of $6 \mathrm{cmH}_{2} \mathrm{O}$, in injured lungs. Overall, our data suggest that the beneficial effect of a moderate level of PEEP was more prominent than that observed with IRV.
One of the most challenging aspects of ventilating patients with ARDS is the tradeoff between maintaining optimal gas exchange with appropriate systemic hemodynamic parameters and regional tissue oxygenation. In this study, we applied a model of lung injury which reproduces the cardinal features of ARDS, with a $\mathrm{PaO}_{2} / \mathrm{FiO}_{2}<200$ [1] and a major reduction in respiratory tissue compliance. To our knowledge, despite extensive studies of the cardiorespiratory effects of IRV [25-30] no data are available on the effects of PEEP and IRV on brain oxygenation in the presence of ARDS, without concomitant brain injury.

The rationale behind the use of IRV is to improve alveolar recruitment by prolonging the time during which positive pressure is applied at the airway opening during inspiration. Lengthening inspiratory time leads to an increase in mean airway pressure, without increasing peak pressures. Therefore, increasing I:E ratio has the 

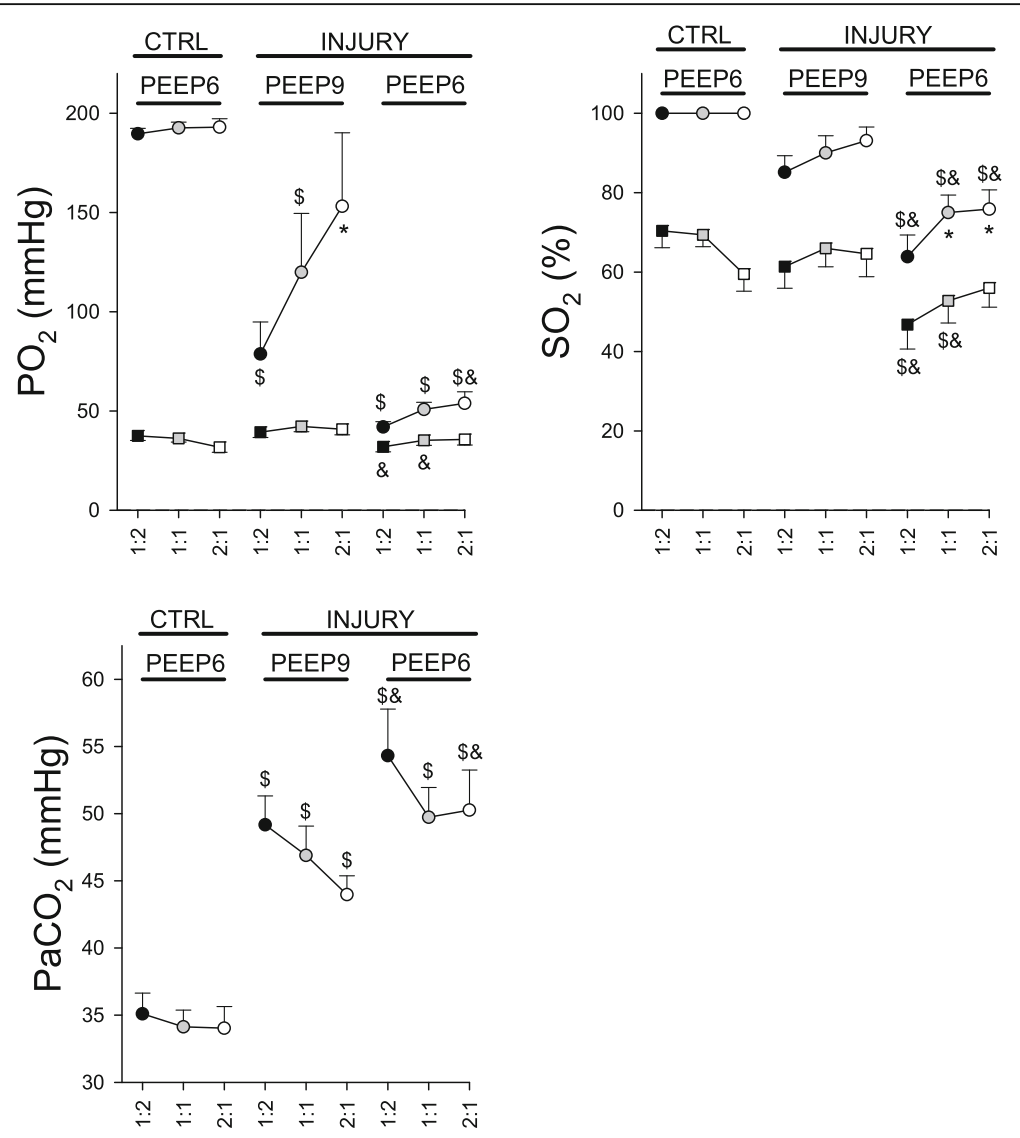

\section{I:E ratio}

Fig. 4 Gas exchange parameters. CTRL: control; $\mathrm{PO}_{2}$ : oxygen partial pressure in arterial and jugular venous blood; $\mathrm{PaCO}_{2}$ : arterial carbon dioxide partial pressure; $\mathrm{SO}_{2}$ : oxygen saturation in arterial and jugular venous blood; circles: values obtained from arterial blood; squares: values obtained from arterial blood; *: vs. 1:2; \$: vs. control; \&: vs. injury at PEEP $9 \mathrm{cmH}_{2} \mathrm{O}$

potential to improve the mechanical properties of the airways and respiratory tissues and gas exchange [25, 26, 28]. However, both PEEP and IRV can potentially reduce venous return due to an increase in intrathoracic pressure, thereby decreasing cardiac output $[27,28]$. Both could contribute to a decrease in CF due to a reduction in effective cerebral perfusion pressure, and in cerebral oxygenation. Examination of the physiological consequences of these modes on cerebral oxygenation are therefore important and relevant. Although IRV is not widely used in clinical practice, recent studies in the literature suggest that it might be used to maintain end-expiratory recruitment without the adverse effects of PEEP [29]. Other ventilation modes have been proposed such as airway pressure-release ventilation (APRV), which is an inverseratio pressure controlled, intermittent mandatory ventilation, that is intensely used in some centers and used as the primary mode in ARDS [31, 32]. This mode bears similarities with IRV in that mean airway pressure is increased through a prolonged inspiratory time, without increasing peak airway pressure [33].
Inverse-ratio ventilation resulted in a net decrease in $\Delta \mathrm{O}_{2} \mathrm{Hb}$ at baseline. In injured lung however, the effect of IRV on brain oxygenation was not significant. These changes may be attributed to the concomitant changes in gas exchange and brain perfusion as measured by $\mathrm{CF}$. In turn, CF depended on MAP and was significantly influenced by $\mathrm{PaCO}_{2}$ (Additional file 1: Figure S1). At baseline, the drop in $\Delta \mathrm{O}_{2} \mathrm{Hb}$ with IRV may be attributed to a decreased carotid flow, while the gas exchange parameters were unchanged. The decrease in CF under IRV in this case, may have resulted from a decreased cardiac output. This is in line with the decrease in MAP. Moreover, the decrease in CVP suggests a reduced venous return with IRV (Fig. 3). Additionally, the decrease in CF was correlated to $\mathrm{Paw}_{\mathrm{m}}$ (Additional file 1: Figure S1). On the other hand, the lack of a significant effect of IRV on $\Delta \mathrm{O}_{2} \mathrm{Hb}$ in ARDS may be due to a concomitant increase in $\mathrm{PaO}_{2}$ and a drop in CF (Figs. 3 and 4) at the higher PEEP level of $9 \mathrm{cmH}_{2} \mathrm{O}$.

In normal lung, the correlations between $\mathrm{CF}$ and brain oxygenation indices (Additional file 1: Figure S1) were 


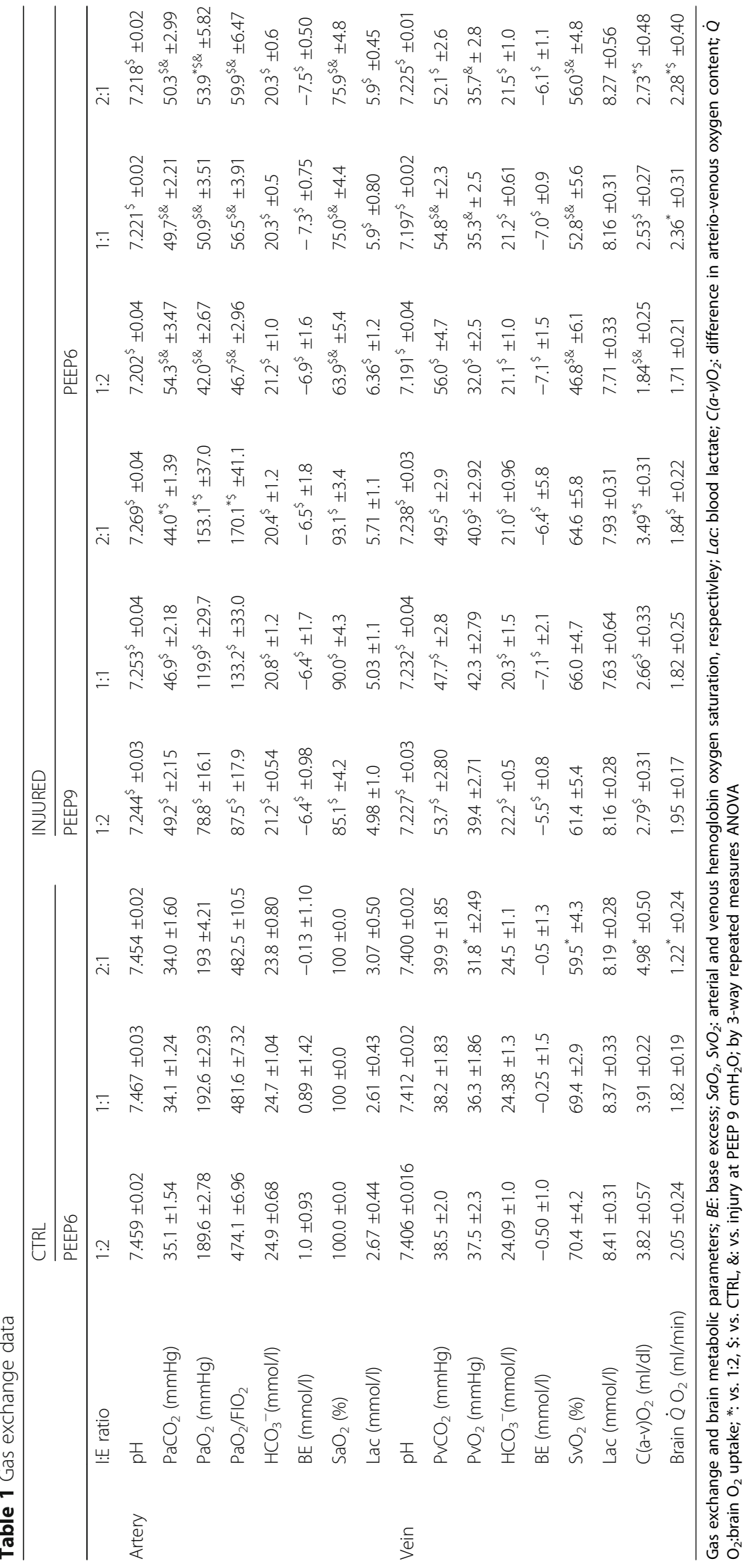



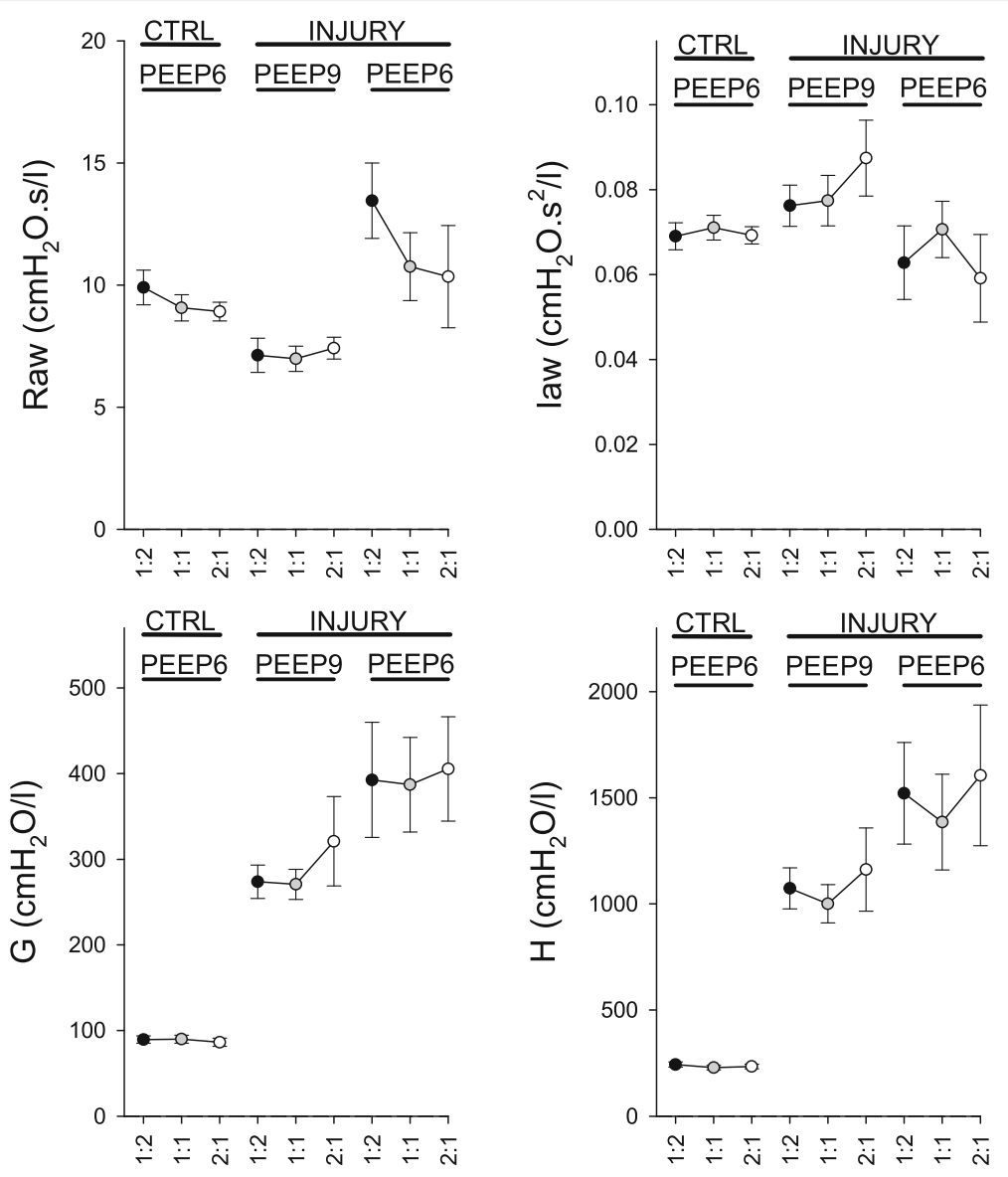

\section{I:E ratio}

Fig. 5 Forced oscillatory respiratory mechanical parameters; Raw: airway resistance; law: airway inertance; H: respiratory tissue elastance; G: respiratory tissue damping; CTRL: control; *: vs. 1:2; \#: vs. 1:1; \$: vs. control; \&: vs. injury at PEEP $9 \mathrm{cmH}_{2} \mathrm{O}$

opposite to those observed in moderate ARDS. This is explained by the fact that the predominant effect of an increase in $\mathrm{Paw}_{\mathrm{m}}$ was a drop in CF, while gas exchange was not significantly affected (Fig. 4). Under this condition, brain oxygenation indices were primarily determined by brain perfusion, which was itself dependent upon the MAP, which is illustrated by a strong correlation between MAP and CF.

In injured lung, IRV significantly increased $\mathrm{PaO}_{2}$ and reduced $\mathrm{PaCO}_{2}$, although this effect was highly dependent on PEEP: a much larger improvement in $\mathrm{PaO}_{2}$ and a reduction in $\mathrm{PaCO}_{2}$ was observed at the higher PEEP level of $9 \mathrm{cmH}_{2} \mathrm{O}$. The lower PEEP level of $6 \mathrm{cmH}_{2} \mathrm{O}$ resulted in a severe hypoxemia and hypercapnia. Despite a higher carotid flow promoted by hypercapnic cerebral vasodilation, brain oxygenation was significantly decreased as a consequence of severe hypoxemia. Under this condition, IRV had no significant effect on brain oxygenation.

A potential mechanism for the improved gas exchange on PEEP $9 \mathrm{cmH}_{2} \mathrm{O}$, may be that small increments in
$\mathrm{Paw}_{\mathrm{m}}$ under IRV, resulted in lung recruitment. However, although a modest increase in PEEP improved respiratory tissue elastance suggesting recruitment, no additional decreases in $\mathrm{H}$ were observed by increasing I:E (Fig. 5). It should be noted that IRV did not produce any intrinsic PEEP at either PEEP levels in injured lung, although a slight intrinsic PEEP was observed at baseline (Fig. 1). Nevertheless, poorly compliant alveoli with faster emptying time constants, that derecruit upon endexpiration are likely to be aerated for longer periods of time during IRV. This mechanism would contribute to gas exchange [34], but would not be measured by respiratory elastance, which is measured upon expiration. However, in injured lung IRV did not significantly increase the dynamic compliance either, despite a significant improvement with the PEEP increment from 6 to $9 \mathrm{cmH} 2 \mathrm{O}$ (Additional file 1: Figure S1). Our data therefore, do not demonstrate a better alveolar recruitment under IRV.

Another possible mechanism for the observed improvement in gas exchange is that the prolonged 
inspiration lengthens the time for admixture of alveolar and dead space gas, thereby reducing physiologic dead space $[25,27,34]$. This effect may have been more prominent in the presence of a larger alveolar gas compartment due to the recruitment induced by the slightly higher PEEP level.

Ventilating the lung with a slightly higher PEEP ( 9 vs. $6 \mathrm{cmH}_{2} \mathrm{O}$ ) with an I:E of 0.5, improved tissue oxygenation markedly in the brain and, to a lesser degree, in peripheral muscle. This effect on brain oxygenation occurred despite a significant decrease in CF (Fig. 3) that occurred in parallel to a reduction in $\mathrm{PaCO}_{2}$, while MAP and CVP were unchanged. This suggests that increased brain oxygenation in this case, was mainly due to improved gas exchange (Fig. 4). This interpretation is further illustrated by the negative correlation between $\mathrm{CF}$ and brain oxygenation indices (TOI, $\Delta \mathrm{HbO}_{2}$ ) in injured lung (Additional file 1: Figure S1).

Our study had several methodological limitations. Only a single PEEP level was tested at baseline. This was because higher PEEP levels are seldom applied in normal lung, and our data show that higher airway pressures in healthy lungs can indeed compromise cerebral perfusion and systemic hemodynamics without improving gas exchange. To avoid the confounding effects of evolving lung injury and limited time, only one PEEP increment was assessed in injured lung. However, the single PEEP increment was sufficient to characterize the effect of elevated PEEP on the brain oxygenation indices; further PEEP elevations would likely produce similar trends with changes of larger magnitude. In this study, we did not alter respiratory rate in order to adjust $\mathrm{PaCO}_{2}$ between the various ventilatory conditions; we rather maintained the same level of external PEEP and minute ventilation, and modified the I:E ratio. While this resulted in changes in physiologic parameters with significant colinearity amongst themselves, this is inherent to in-vivo studies in general and similar to the comparison of standard I:E and IRV in the clinical setting [27]. Moreover, manipulating the respiratory rate would have modified $\mathrm{Paw}_{\mathrm{m}}$ raising further issues. We therefore maintained a study design that allows assessing the integral effect of manipulating I:E on cerebral oxygenation. We did not measure cardiac output, and it should be noted that CVP may be a weak indicator of volume status [35], although it has been shown to decrease with hypovolemia and rise with resuscitation in rabbits [36]. However, the drop in MAP is highly suggestive of a drop in cardiac output under IRV at baseline. Finally, as in any study using animal models, extrapolation to human subjects should be made with appropriate caution. However, cerebrovascular autoregulation in rabbit has been widely used as a consistent model of human physiology $[37,38]$.

\section{Conclusions}

We found that the mechanical ventilation strategy in the presence of lung injury significantly impacted brain oxygenation. In normal lung, IRV had a deleterious effect on brain oxygenation, and clinicians should be aware of the potential adverse effect of this ventilation mode. Moreover, we observed no effect of IRV on brain oxygenation in moderate ARDS, as the beneficial effects of IRV on gas exchange were counteracted by decreases in cerebral perfusion. In contrast, a modest PEEP significantly improved brain oxygenation in injured lung, since the substantial improvement in gas exchange overcame the concomitant decrease in brain perfusion. Overall, our data suggest that unlike moderate PEEP, IRV is not effective in improving brain oxygenation in ARDS.

\section{Additional file}

Additional file 1: Figure S1. Correlations between airway pressures and brain tissue oxygenation, perfusion, and hemo-dynamic, gas exchange parameters. (DOCX 294 kb)

\section{Abbreviations}

APRV: Airway pressure-release ventilation; ARDS: Acute respiratory distress syndrome; CF: Carotid flow; ECG: Electrocardiogram; ET-cannula: Endotracheal cannula; $\mathrm{ETCO}_{2}$ : End-tidal $\mathrm{CO}_{2} ; \mathrm{FiO}_{2}$ : Fraction of inspired $\mathrm{O}_{2}$; G: respiratory tissue damping; $\mathrm{H}$ : respiratory tissue elastance; I:E: Ratio of inspirartory/ expiratory time; law: Respiratory inertance; IRV: Inverse-ration ventilation; MAP: Mean arterial pressure; NIRS: Near-infrared spectroscopy; $\mathrm{PaO}_{2}$ : arterial $\mathrm{O}_{2}$ partial pressure; PEEP: Positive end-expiratory pressure; PIP: Peak inspiratory pressure; Raw: Airway resistance; RR: Respiratory rate; TOI: Tissue oxygenation index; VT: tidal volume; Zrs: respiratory impedance; $\Delta \mathrm{HbO}_{2}$ : change in oxygenated hemoglobin; $\Delta \mathrm{HHO}_{2}$ : change in deoxygenated hemoglobin

\section{Acknowledgements}

The authors thank Xavier Belin and Sylvie Roulet for their technical assistance.

\section{Authors' contributions}

$\mathrm{SB}, \mathrm{FL}, \mathrm{FP}$, and $\mathrm{WH}$ designed the study; SB and FL acquired the data; SB, FL, GHF and FP carried out the data analysis; SB, FL, FP and WH drafted the manuscript. All authors read, edited and approved the final version of the article.

\section{Funding}

This study was funded by a research grant from the University Hospitals of Geneva, Switzerland, and the Swiss National Science Foundation Grant (32003B_169334). No funding body had any role in the design of the study; collection, analysis, and interpretation of data; and in writing the manuscript.

\section{Availability of data and materials}

The datasets used and/or analysed during the current study are available from the corresponding author on reasonable request.

Ethics approval and consent to participate

All experiments and procedures were conducted under approval from the Swiss Animal Welfare Committee (Geneva Cantonal Veterinary Office,

registration number GE/164/15).

Consent for publication

Not applicable.

Competing interests

The authors declare that they have no competing interests. 


\section{Author details}

'Unit for Anesthesiological Investigations Department of Anesthesiology Pharmacology and Intensive Care, University of Geneva, Geneva, Switzerland. ${ }^{2}$ University of Milano-Bicocca, Milan, Italy. ${ }^{3}$ Department of Medical Physics and Informatics, University of Szeged, Szeged, Hungary. ${ }^{4}$ Pediatric Anesthesia Unit, Geneva Children's Hospital, Geneva, Switzerland. ${ }^{5}$ Inserm UA7 STROBE Laboratory, University of Grenoble, Grenoble, France. ${ }^{6}$ Department of Clinical Physiology, Sleep and Exercise, Grenoble University Hospital, Grenoble, France.

Received: 13 September 2018 Accepted: 9 June 2019 Published online: 19 June 2019

\section{References}

1. Ranieri VM, Rubenfeld GD, Thompson BT, Ferguson ND, Caldwell E, Fan E, et al. Acute respiratory distress syndrome: the Berlin definition. JAMA. 2012;307(23):2526-33.

2. Wang C, Wang X, Chi C, Guo L, Zhao N, Wang W, et al. Lung ventilation strategies for acute respiratory distress syndrome: a systematic review and network meta-analysis. Sci Rep. 2016;6:22855.

3. Gattinoni L, Carlesso E, Caironi P. Stress and strain within the lung. Curr Opin Crit Care. 2012;18(1):42-7.

4. Protti A, Cressoni M, Santini A, Langer T, Mietto C, Febres D, et al. Lung stress and strain during mechanical ventilation: any safe threshold? Am J Respir Crit Care Med. 2011;183(10):1354-62.

5. Briel M, Meade M, Mercat A, Brower RG, Talmor D, Walter SD, et al. Higher vs lower positive end-expiratory pressure in patients with acute lung injury and acute respiratory distress syndrome: systematic review and metaanalysis. JAMA. 2010;303(9):865-73.

6. Brower RG, Lanken PN, Maclntyre N, Matthay MA, Morris A, Ancukiewicz M, et al. Higher versus lower positive end-expiratory pressures in patients with the acute respiratory distress syndrome. N Engl J Med. 2004;351(4):327-36.

7. Zhang WP, Zhu SM. The effects of inverse ratio ventilation on cardiopulmonary function and inflammatory cytokine of bronchoaveolar lavage in obese patients undergoing gynecological laparoscopy. Acta Anaesthesiol Taiwanica : Off J Taiwan Soc Anesthesiol. 2016;54(1):1-5.

8. Armstrong BW Jr, Maclntyre NR. Pressure-controlled, inverse ratio ventilation that avoids air trapping in the adult respiratory distress syndrome. Crit Care Med. 1995;23(2):279-85.

9. Wang $X$, Wang $P$, Wang $K$, Jiang T, Xu Z. Pressure-controlled inverse ratio ventilation during general anesthesia for open abdominal surgery improves postoperative pulmonary function. J Biomed Sci Eng. 2016;9(01):17.

10. Lessard MR, Guerot E, Lorino H, Lemaire F, Brochard L. Effects of pressurecontrolled with different I:E ratios versus volume-controlled ventilation on respiratory mechanics, gas exchange, and hemodynamics in patients with adult respiratory distress syndrome. Anesthesiology. 1994;80(5):983-91.

11. Gore DC. Hemodynamic and ventilatory effects associated with increasing inverse inspiratory-expiratory ventilation. J Trauma. 1998:45(2):268-72.

12. Michard F, Teboul JL. Using heart-lung interactions to assess fluid responsiveness during mechanical ventilation. Crit Care. 2000:4(5):282-9.

13. Yarowsky PJ, Ingvar DH. Symposium summary. Neuronal activity and energy metabolism. Fed Proc. 1981:40(9):2353-62.

14. Lassen NA. Cerebral blood flow and oxygen consumption in man. Physiol Rev. 1959:39(2):183-238.

15. Joshi B, Ono M, Brown C, Brady K, Easley RB, Yenokyan G, et al. Predicting the limits of cerebral autoregulation during cardiopulmonary bypass. Anesth Analg. 2012;114(3):503-10.

16. Schramm P, Closhen D, Felkel M, Berres M, Klein KU, David M, et al. Influence of PEEP on cerebral blood flow and cerebrovascular autoregulation in patients with acute respiratory distress syndrome. J Neurosurg Anesthesiol. 2013;25(2):162-7.

17. Hopkins RO, Jackson JC. Long-term neurocognitive function after critical illness. Chest. 2006;130(3):869-78.

18. Pelosi P, Rocco PR. The lung and the brain: a dangerous cross-talk. Crit Care 2011;15(3):168

19. Hopkins RO, Myers CE, Shohamy D, Grossman S, Gluck M. Impaired probabilistic category learning in hypoxic subjects with hippocampal damage. Neuropsychologia. 2004:42(4):524-35.

20. Suzuki S, Takasaki S, Ozaki T, et al. A tissue oxygenation monitor using NIR spatially resolved spectroscopy, vol. 11. Bellingham, WA, ETATS-UNIS: Society of Photo-Optical Instrumentation Engineers; 1999.
21. Bayat S, Strengell S, Porra L, Janosi TZ, Petak F, Suhonen $H$, et al. Methacholine and ovalbumin challenges assessed by forced oscillations and synchrotron lung imaging. Am J Respir Crit Care Med. 2009;180(4):296-303.

22. Hantos Z, Daroczy B, Suki B, Nagy S, Fredberg JJ. Input impedance and peripheral inhomogeneity of dog lungs. J Appl Physiol. 1992;72(1):168-78.

23. Bates $D$, Mächler $M$, Bolker B. Walker S. fitting linear mixed-effects models using Ime4. 2015. 2015;67(1):48.

24. Lenth RV. Least-squares means. The R Package Ismeans 2016. 2016;69(1):33.

25. Cole AG, Weller SF, Sykes MK. Inverse ratio ventilation compared with PEEP in adult respiratory failure. Intensive Care Med. 1984;10(5):227-32.

26. Yanos J, Watling SM, Verhey J. The physiologic effects of inverse ratio ventilation. Chest. 1998;114(3):834-8.

27. Mercat A, Titiriga M, Anguel N, Richard C, Teboul JL. Inverse ratio ventilation $(I / E=2 / 1)$ in acute respiratory distress syndrome: a six-hour controlled study. Am J Respir Crit Care Med. 1997:155(5):1637-42.

28. Neumann P, Berglund JE, Andersson LG, Maripu E, Magnusson A, Hedenstierna $G$. Effects of inverse ratio ventilation and positive endexpiratory pressure in oleic acid-induced lung injury. Am J Respir Crit Care Med. 2000;161(5):1537-45.

29. Boehme S, Bentley AH, Hartmann EK, Chang S, Erdoes G, Prinzing A, et al Influence of inspiration to expiration ratio on cyclic recruitment and derecruitment of atelectasis in a saline lavage model of acute respiratory distress syndrome. Crit Care Med. 2015;43(3):e65-74.

30. Muller-Redetzky HC, Felten M, Hellwig K, Wienhold SM, Naujoks J, Opitz B, et al. Increasing the inspiratory time and I:E ratio during mechanical ventilation aggravates ventilator-induced lung injury in mice. Crit Care. 2015;19:23.

31. Habashi NM. Other approaches to open-lung ventilation: airway pressure release ventilation. Crit Care Med. 2005;33(3 Suppl):S228-40.

32. Jain SV, Kollisch-Singule M, Sadowitz B, Dombert L, Satalin J, Andrews $P$, et al. The 30-year evolution of airway pressure release ventilation (APRV). Intensive Care Med Exp. 2016:4(1):11.

33. Mireles-Cabodevila E, Kacmarek RM. Should airway pressure release ventilation be the primary mode in ARDS? Respir Care. 2016;61(6):761-73.

34. Knelson JH, Howatt WF, DeMuth GR. Effect of respiratory pattern on alveolar gas exchange. J Appl Physiol. 1970;29(3):328-31.

35. Kumar A, Anel R, Bunnell E, Habet K, Zanotti S, Marshall S, et al. Pulmonary artery occlusion pressure and central venous pressure fail to predict ventricular filling volume, cardiac performance, or the response to volume infusion in normal subjects. Crit Care Med. 2004;32(3):691-9.

36. Chen S, Zhu X, Wang Q, Li W, Cheng D, Lei C, et al. The early effect of Voluven, a novel hydroxyethyl starch (130/0.4), on cerebral oxygen supply and consumption in resuscitation of rabbit with acute hemorrhagic shock J Trauma. 2009:66(3):676-82

37. Aksenov D, Eassa JE, Lakhoo J, Wyrwicz A, Linsenmeier RA. Effect of isoflurane on brain tissue oxygen tension and cerebral autoregulation in rabbits. Neurosci Lett. 2012;524(2):116-8.

38. Tureen JH, Dworkin RJ, Kennedy SL, Sachdeva M, Sande MA. Loss of cerebrovascular autoregulation in experimental meningitis in rabbits. J Clin Invest. 1990:85(2):577-81.

\section{Publisher's Note}

Springer Nature remains neutral with regard to jurisdictional claims in published maps and institutional affiliations. 